\title{
FIBER OPTIC AIDED SPECTROPHOTOMETRIC DETERMINATION OF GADOLINIUM IN FBR REPROCESSING STREAMS
}

\author{
S.Ganesh, N.K.Pandey \\ Reprocessing Research and Development Division, Reprocessing Group, Indira Gandhi \\ Centre for Atomic Research, Kalpakkam 603 102, Tamilnadu, India
}

\begin{abstract}
A new spectrophotometric method has been developed for the quantitative analysis of gadolinium using 1 , 2-dihydroxy anthraquinone-3-sulphonic acid, sodium salt (Alizarin Red S). Influence of various parameters such as concentration of complexing agent, $\mathrm{pH}$, and interference of other competing metal ions was examined in a systematic manner. Gadolinium is found to be a stable complex as Gd-ARS at pH 4.6-4.8 and having a maximum absorbance at $530 \mathrm{~nm}$. Beer's law was found to be obeyed in 1 to $14 \mu \mathrm{g} / \mathrm{mL}$ range of gadolinium with a correlation coefficient of $R^{2}=0.9992(n=14)$. The system allowed for the determination of gadolinium with a limit of detection (LOD) $(3.3 \sigma / S)$ of $0.264 \mu \mathrm{g} / \mathrm{mL}$, limit of quantitation $(L O Q)(10 \sigma / S)$ of $0.8 \mu \mathrm{g} / \mathrm{mL}$. The precision expressed as relative standard deviation (RSD) of $0.38 \%$ and $1.96 \%$ at 5.4

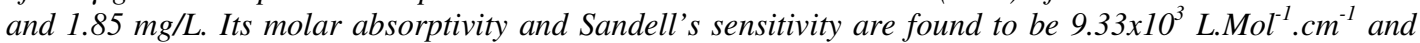
$1.07 \times 10^{-4} \mu \mathrm{g} / \mathrm{cm}^{2}$ respectively. An easy and versatile determination of gadolinium concentration during the solvent extraction study of Gadolinium with $30 \%$ tri-n-butyl phosphate-nitric acid system is proposed.
\end{abstract}

\section{KEY WORDS:}

Gadolinium, Alizarin Red S, Spectrophotometry, Molar Absorptivity, Extraction

\section{INTRODUCTION}

The reprocessing of irradiated plutonium-rich mixed carbide fuel from Fast Breeder Test Reactor (FBTR) is being carried out by modified PUREX process in pilot plant, named CORAL (COmpact Reprocessing of Advanced fuel in Lead shielded facility) [1]. Criticality is a major challenging issue to be addressed at each stage of PUREX process. The probability of criticality is higher in plutonium rich Fast Breeder Reactor fuel reprocessing compared to that of thermal reactor spent fuel reprocessing. Generally, the safety measures are taken to prevent the criticality incident, either by controlling geometry of equipments, mass or concentration of plutonium or combination of both may also used. The process steps are operated in batch or continuous mode. The continuous mode process is still under development. An alternated method is required to ensure critically safe reprocessing of high plutonium content fuels. Hence addition of soluble neutron poisons [2-3] as a primary control has economic advantage as it has no restriction on vessel size, shape and solution concentrations. Among the few potential candidates, Gadolinium is found to be the best possible choice as soluble neutron poison due to its high neutron absorption cross section, adequately high solubility in nitric acid and chemical compatibility in the PUREX solvent extraction process conditions [3]. Apart from these, gadolinium has well known applications in nuclear industry (fuel and control rod), fabrication of refractory materials in ceramic industries [3-4]. Its oxide is largely used as shielding and fluxing devices.

In view of the above facts, it is important to know the extraction behavior in various streams of nuclear fuel reprocessing and in allied waste management process. In majority of the process stages, the amount of gadolinium present is very less concentration and need to have a highly sensitive, robust and easy method having low detection limit to determine the concentration of

DOI: 10.5121/ijac.2017.3201 
gadolinium in both organic and aqueous medium. Numerous analytical techniques such as inductively coupled plasma mass spectrometry [5], inductively coupled plasma mass and atomic emission spectrometry [6], X-ray fluorescence spectrometry [7], electron spin resonance [8], neutron activation analysis [9], fluorescence spectrometry [10], phosphorescence [11] and Liquid membrane sensor [12] etc are reported in the literature. However, majority of these instruments are costly and needs high caring during the analysis. On the other hand, more popular and economical spectrophotometric determination of gadolinium with variety of chromogenic reagents such as Xylenol Orange [13], Arsenazo (III) [14-15], poly[dibenzo-18-crown-6] [16], tetra ethylene penta amine hepta acetic acid (TPHA) [17], 1-(2-pyridylazo)-2-naphthol (PAN) [18], Di-n-buthyl dithiocarbamate [19], 1,10-Phenantroline [20], 2-(5-bromo-2-pyridyl 5diethylazo)-diethylamine phenol (Br-PADAP) [21] and direct [22] are being used. The aim of present communication is to highlight the development of new spectrophotometric method for the determination of gadolinium present in nitric acid medium. In addition, this method can be employed for the determination of gadolinium in various streams of PUREX process.

Using this technique, the concentration of gadolinium in organic and aqueous streams in solvent extraction step and to determine the distribution coefficient of gadolinium in nitric acid-30\% TBP system at various acidity and concentration of gadolinium is highlighted.

\section{EXPERIMENTAL}

\subsection{Instrumentation}

Indigenously developed fiber optic aided spectrophotometer with $1 \mathrm{~cm}$ path length dip type probe is used to measure the absorbance. "Chemlabs", Bangalore, make Micro-07; $\mathrm{pH} / \mathrm{mV}$ meter coupled with glass electrode was used for $\mathrm{pH}$ measurements.

\subsection{Chemicals and reagents}

All the chemical and reagents used in the present study were of analytical grade. Doubly distilled de-ionizedwater, which is non-absorbent under ultraviolet radiation, was used throughout. Glass vessels were cleaned by soaking in acidifiedsolutions of $\mathrm{KMnO}_{4}$ or $\mathrm{K}_{2} \mathrm{Cr}_{2} \mathrm{O}_{7}$ followed by washingwith nitric acid (1:1) and rinsed several times with high-purity de-ionized water. A stock solution of gadolinium (III) nitrate $(1000 \mu \mathrm{g} / \mathrm{mL})$ was prepared by dissolving gadolinium (III) nitrate of $99.9 \%$ purity (obtained from $\mathrm{M} / \mathrm{s}$ Alfa Aesar Chemicals) in $1 \mathrm{M}$ nitric acid. Buffer solution of $\mathrm{pH}$ 4.6-4.7 was prepared by dissolving $8.8 \mathrm{~g}$ of L-Ascorbic acid and $1.6 \mathrm{~g}$ of sodium hydroxide together in $100 \mathrm{~mL}$ distilled water. $0.05 \%$ Alizarin Red S (ARS) was prepared by dissolving sodium salt of 1, 2-dihydroxy anthraquinone-3-sulphonic acid, (obtained from Merck, India) in distilled water.Standard solutions of nitric acid (Merck) were prepared by diluting concentrated nitric acid.

\subsection{Procedure}

Suitable aliquots containing 1-14 $\mu \mathrm{g}$ of Gd(III) were taken into $10 \mathrm{~mL}$ standard flasks and $2 \mathrm{~mL}$ of $0.05 \%$ ARS solution, $0.5 \mathrm{~mL}$ of the buffer solution ( $\mathrm{pH} 4.6$ ) were added to each flasks and made volume up to mark with $1 M$ nitric acid. The absorbance of the solutions was measured from 650$380 \mathrm{~nm}$ against a reagent blank prepared under identical conditions.

\subsection{Results and discussion}

The possible chemical structure of Gd-ARS [23] and schematic diagram of reaction with gadolinium for the spectrophotometric detection are illustrated in Fig.1. The advantageof ARS over other chromogenic reagents are, water solubility and the ability to form gadolinium complex even in high acidic solutions. Optimization of experimental conditions for determination of gadolinium is represented in table 1 . 
International Journal of Advances in Chemistry (IJAC) Vol. 3, No.1/ 2, May 2017

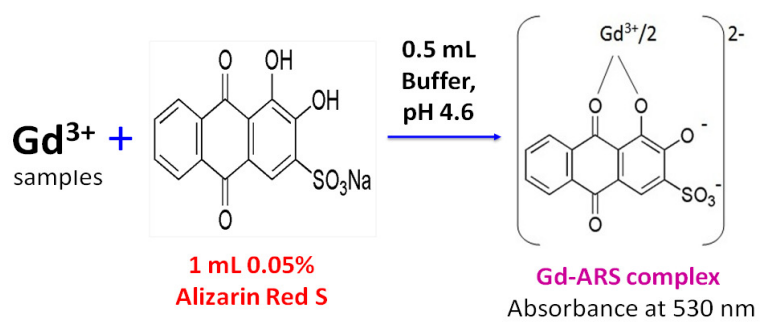

Fig 1 possible chemical structure of Gd-ARS complex at $\mathrm{pH} 4.6$

Table 1 Spectral characteristics of Gd-AR S complex

\begin{tabular}{ll} 
& \\
\hline Parameter & Gd-ARS complex \\
\hline$\lambda_{\text {maxs }}(\mathrm{nm})$ & 530 \\
Molar absorptivity, $\left(\mathrm{L}^{\mathrm{M}} \mathrm{Mol}^{-1} \cdot \mathrm{cm}^{-1}\right)$ & $9.33 \times 10^{3}$ \\
Sandell's sensitivity $\left(\mu \mathrm{g} / \mathrm{cm}^{2}\right)$ & $1.07 \times 10^{-4}$ \\
Detection Limit $(\mu \mathrm{g} / \mathrm{mL})$ & 0.264 \\
Quantitation Limit $(\mu \mathrm{g} / \mathrm{mL})$ & 0.8 \\
LinearRange $(\mu \mathrm{g} / \mathrm{mL})$ & $1-14$ \\
Stability formation region $(\mathrm{pH})$ & $4.6-4.8$ \\
L-Ascorbic acid \& NaOH buffer & 0.5 \\
$(m L)$ & 1 \\
Alizarin Red S $(0.05 \%)(\mathrm{mL})$ & \\
\hline
\end{tabular}

\section{Spectral Characteristics}

ARS reacts with gadolinium (III) and forms a stable reddish purple colour complex almost instantaneously in aqueous medium at $\mathrm{pH}$ 4.6-4.8. The complex is stable for 24 hours. Typical absorption spectrum is a symmetric curve with maximum absorbance $\left(\lambda_{\max }=530 \mathrm{~nm}\right)$ was shown in Fig. 2. In all instances measurements were made at $530 \mathrm{~nm}$ against a reagent blank.

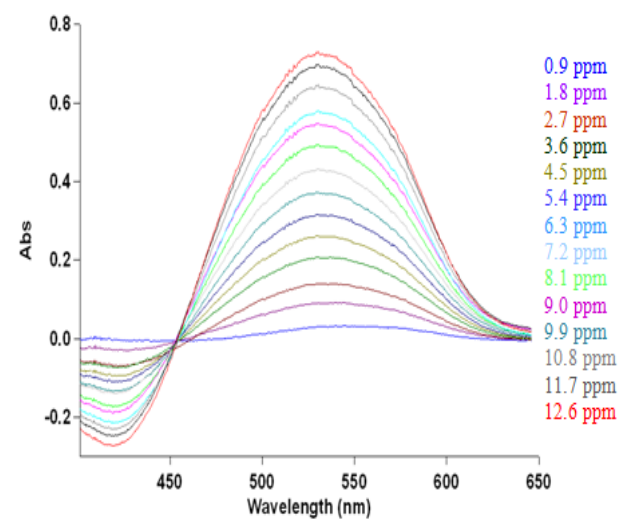

Fig.2 Typical absorption spectrum of Gd-ARS complex at $\mathrm{pH}$ 4.6-4.8

\section{CAlibration Graph, BeER's LAW AND SENSITIVITY}

A series of standard gadolinium solutions were prepared and the absorbance of each was measured and plotted against concentration. The well-known equation for spectrophotometric analysis in very dilute solution was derived from Beer's law. The calibration curve of Gd-ARS complex with fixed ARS (0.05\%) to form Gd-ARS at $530 \mathrm{~nm}$ (Fig 3) shows that Beer's law is 
obeyed in the concentration range of $1-14 \mu \mathrm{g} / \mathrm{mL}$. The linear regression equation obtained was: A $=0.0662 \times \mathrm{C}_{\mathrm{Gd}(\mu g / m L)}-0.0175$, with a correlation coefficient of $0.9997\left(\mathrm{R}^{2}=0.9997\right)$. The complex has a maximum absorbance at $530 \mathrm{~nm}$ with molar extinction coefficient and Sandell's sensitivity

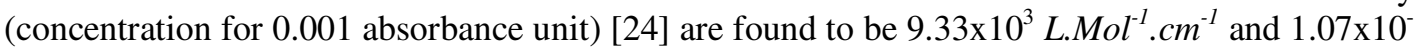
${ }^{4} \mu \mathrm{g} / \mathrm{cm}^{2}$ respectively.

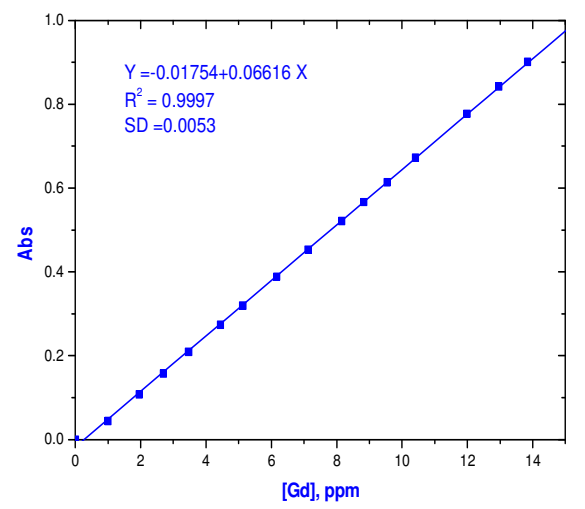

Fig 3 Typical Calibration graph for determination of Gd (III) nitrate with ARS at $530 \mathrm{~nm}$

\section{DETECTION LIMIT AND QUANTITATION LIMIT}

The limit of detection has been calculated as $(3.3 \sigma / \mathrm{S})$, where $\sigma$ denotes the standard deviation for blank $(n=12)$ and $S$ stands for the slope of the analytical curve from calibration graph. The limit of detection (LOD) was found to be $0.264 \mu \mathrm{g} / \mathrm{mL}$, where as the limit of quantitation (LOQ) $(10 \sigma / \mathrm{S})$ was $0.8 \mu \mathrm{g} / \mathrm{mL}$ with precision (was evaluated by determination of different concentration of gadolinium) expressed as relative standard deviation (RSD) of $0.38 \%$ and $1.96 \%$ at 5.4 and $1.85 \mu \mathrm{g} / \mathrm{mL}$ respectively. The obtained results indicate that this method is highly precise and reproducible. Calculations were made the recommendations by IUPAC [25]. The best agreement between theoretically computed and practically verified values of LOD and LOQ was approaches namely at significance level $\alpha=0.05$.

\section{EFFect Of Ph Solution}

The $\mathrm{pH}$ of the solution has a great influence on the absorbance of the Gd-ARS Complex. The $\mathrm{pH}$ of the reaction mixture was varied from 2 to 12 and the absorbance was found to be maximum, in the $\mathrm{pH}$ range 4.0 to 4.5 (Fig.4). Hence $\mathrm{pH} 4.5$ was found to be most suitable for maintaining $\mathrm{pH}$ and ascorbic acid/sodium hydroxide buffer solution was employed as optimum for all subsequent work. The use of ascorbate buffer in the present method eliminates the need for the addition of external reducing agent. 


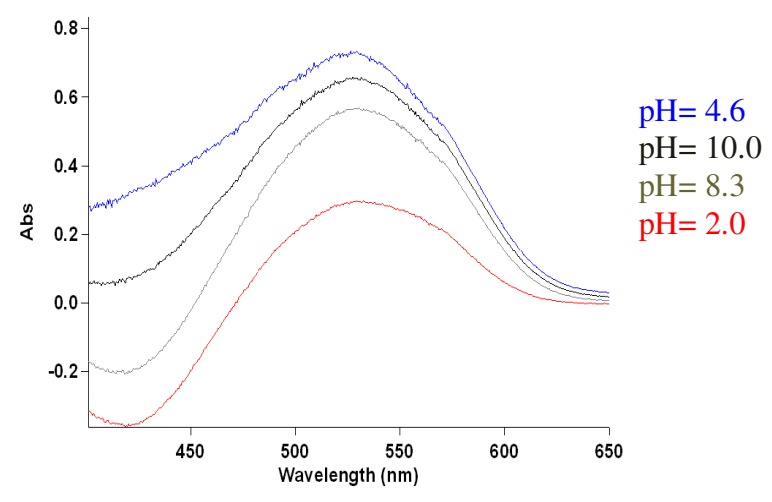

Fig 4. Absorption spectrum of Gd-ARS complex at various $\mathrm{pH}$ values

\section{EFFECT OF BUFFER SOLUTION}

Fig 5 shows the influence of the concentration of buffer solution on the absorbance of Gd-ARS complex. And there is a significant effect of the buffer solution on the system. $0.5 \mathrm{~mL}$ of buffer solution is sufficient for maximum absorbance. If more then, no significant effect was observed. Thus, $0.5 \mathrm{~mL}$ of buffer solution was employed for all studies.

\section{EFFECT OF ARS DYE CONCENTRATION ON OPTIMUM GD-ARS COMPLEX FORMATION}

The study of alizarin red S dye concentration was important for optimum complex formation and its stability. In general dye concentration, less or higher than the required amount, would cause deviation from Beer's law and overlapping of dye spectra with other ion-dye complex. In order to optimize the concentration of $0.05 \%$ ARS, a series of solution containing fixed $\mathrm{Gd}^{3+}$ concentration, fixed buffer solution and different volume of ARS from 1 to $3 \mathrm{~mL}$ to form GdARS complex at $\mathrm{pH}$ 4.6. From Fig. 6, it was found that the maximum absorbance was the most obvious when adding $2 \mathrm{~mL}$ dye at $530 \mathrm{~nm}$, once it exceeds this volume, absorbance would constant. So $2 \mathrm{~mL}$ of ARS is favorable and used in subsequent experiments.

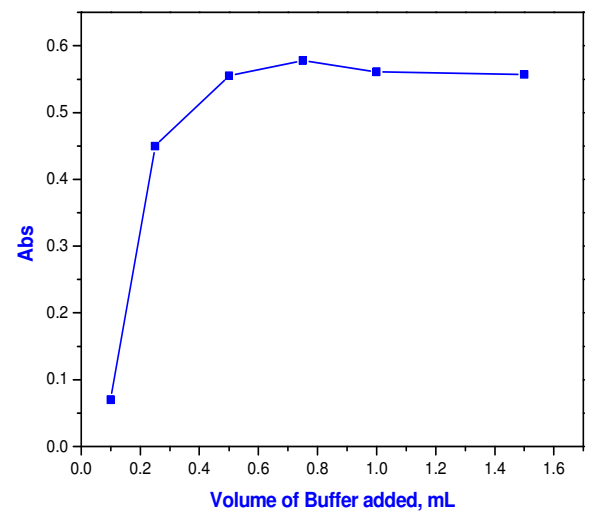

Fig 5. Effect of volume of buffer solution on the absorbance of gadolinium estimation 


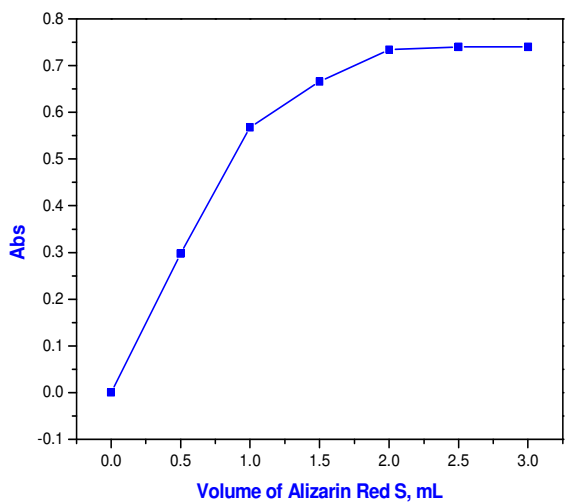

Fig 6. Effect of ARS on the absorbance of gadolinium estimation

\section{STABILITY}

The formation of the coloured complex of gadolinium with alizarin red s was instantaneous. Measurement of the absorbance was therefore carried out immediately after mixing the gadolinium and alizarin red $\mathrm{s}$ and the complex was found to be stable for 24 hours. Freshly prepared buffer solution should be used for measurement of absorbance.

\section{EFFECT OF FOREIGN IONS}

In order to investigate its selectivity and potential analytical application for gadolinium, the influence of various metal ions on the determination of gadolinium with the proposed method was studied under the experimental conditions used. The obtained results listed in table 2 are the tolerance limits of divalent and trivalent metal ions that caused an error are summarized. Sm (III), $\mathrm{Nd}$ (III) and Y (III) interfered seriously with analysis of gadolinium and their interference can be eliminated by prior separation.

\begin{tabular}{|c|c|c|c|c|}
\hline \multicolumn{2}{|c|}{ Interference of metal ions } & \multirow{2}{*}{$\begin{array}{l}\text { Concentration } \\
(\mu g / m L) \\
\text { Taken }\end{array}$} & \multirow{2}{*}{$\begin{array}{l}\text { of Gadolinium } \\
\text { Obtained }\end{array}$} & \multirow[t]{2}{*}{$\%$ error } \\
\hline Metal & $\begin{array}{l}\text { Conc. } \\
(\mu g / m L)\end{array}$ & & & \\
\hline $\mathrm{Sr}\left(\mathrm{NO}_{3}\right)_{3}$ & 50 & 9.4745 & 9.398 & 0.81 \\
\hline $\mathrm{Zr}\left(\mathrm{NO}_{3}\right)_{4}$ & 20 & 9.4745 & 9.351 & 1.30 \\
\hline $\mathrm{UO}_{2}\left(\mathrm{NO}_{3}\right)_{2}$ & 20 & 9.4745 & 9.378 & 1.01 \\
\hline $\mathrm{Sm}\left(\mathrm{NO}_{3}\right)_{3}$ & 15 & 9.4745 & 8.744 & 7.7 \\
\hline $\mathrm{Nd}\left(\mathrm{NO}_{3}\right)_{3}$ & 15 & 9.4745 & 8.492 & 10.3 \\
\hline $\mathrm{Y}\left(\mathrm{NO}_{3}\right)_{3}$ & 15 & 9.4745 & 7.834 & 17.3 \\
\hline
\end{tabular}

\section{Validation Of The Present Method}

The precision and accuracy of the method were tested by taking known two different trace amounts of gadolinium. As shown in table 3, mean values were obtained with Student's t-values at $95 \%$ confidence level and the variance ratio F-values calculated $(\mathrm{p}=0.05)$ for 12 degree of freedom. The results showed comparable accuracy (t-test) and precision (F-test) and did not exceed the theoretical values, indicating that there was no significant difference in accuracy and precision. 
The performance of the proposed method was verified with of other existing UV-Vis spectrophotometric method using Br-PADAP as chromogenic reagent reported in literature [21]. It is clear from the table 4, that the calculated $t$ value is less than the tabulated $t$ value at the $95 \%$ confidence level for four degree of freedom is 2.776. Therefore, $t_{c a l}<t_{\text {table }}$, and there is no significant difference between the two methods at this confidence level. The proposed method is simple and requires less time to complete the analysis. The method is simple, fast, versatile, accurate and useful due to high tolerance limits from cations and anions.

\begin{tabular}{|c|c|c|c|c|}
\hline & $\begin{array}{l}\text { Variable } 1 \\
\text { Present } \\
\text { Method }\end{array}$ & $\begin{array}{l}\text { Reference } \\
\text { Method }\end{array}$ & $\begin{array}{l}\text { Variable } 2 \\
\text { Present Method }\end{array}$ & $\begin{array}{l}\text { Reference } \\
\text { Method }\end{array}$ \\
\hline Mean & 5.4058 & 5.416 & 1.8517 & 1.8529 \\
\hline Standard Deviation & 0.0207 & 0.2095 & 0.0364 & 0.0385 \\
\hline Variance & 0.00042 & 0.000844 & 0.0013 & 0.0014 \\
\hline RSD & 0.38 & 0.39 & 1.96 & 2.08 \\
\hline Degree of freedom & 12 & 12 & 12 & 12 \\
\hline $\mathrm{Df}$ & 22 & & 22 & \\
\hline$f$-Test cal & 1.9719 & & 1.08 & \\
\hline$f$-Test table & 2.98 & & 2.98 & \\
\hline p (Probability) & 0.05 & & 0.05 & \\
\hline$f_{\mathrm{cal}}<f_{\mathrm{table}}$ & \multicolumn{4}{|c|}{ No significant different } \\
\hline Confidence level & \multicolumn{2}{|c|}{$95 \%$} & \multicolumn{2}{|l|}{$95 \%$} \\
\hline$t$-Test cal & \multicolumn{2}{|l|}{0.99} & \multicolumn{2}{|l|}{2.42} \\
\hline$t$-Test table & \multicolumn{2}{|l|}{2.228} & \multicolumn{2}{|l|}{2.28} \\
\hline$t_{\mathrm{cal}}<t_{\mathrm{tab} l \mathrm{a}}$ & \multicolumn{4}{|c|}{ No significant different } \\
\hline
\end{tabular}

\section{APPLiCATIONS}

The proposed method was examined to the determination of gadolinium concentration during the solvent extraction behavior of it with $\mathrm{TBP}-\mathrm{HNO}_{3}$ system at conditions prevalent in FBR fuel reprocessing. Batch experiments were carried out by equilibrating equal volumes of TBP in $\mathrm{nDD}$ with gadolinium nitrate solutions in stopped centrifugal vial for effective mixing using a vortex shaker of Heidolph Reax made at a speed of $1700 \mathrm{rpm}$ for 30 minutes. The two phases were then allowed to disengage completely. After phase separation, the acidity and gadolinium concentration were measured, with appropriate dilution if necessary. The free acidity of both phases was estimated using titration with standard sodium carbonate. The distribution coefficient of gadolinium $\left(D_{\mathrm{Gd}}\right)$ was determined by the ratio of concentration of gadolinium in organic to aqueous phase at equilibrium.

Table 4 Comparison of two different spectrophotometric techniques for determination of gadolinium (paired $\mathrm{t}$ - test)

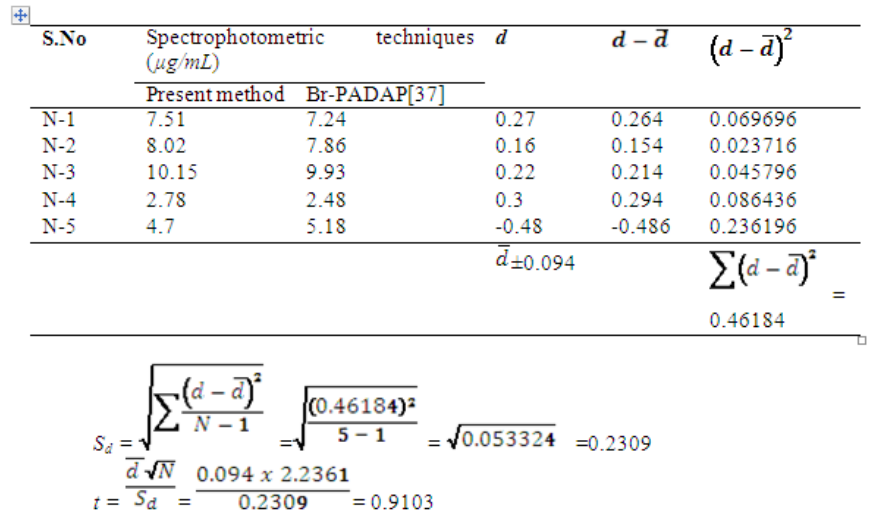




\section{Distribution CoefFicients Of GadoliniUm Nitrate}

The extraction behavior of $\mathrm{Gd}$ (III) in $\mathrm{TBP}-\mathrm{HNO}_{3}$ system is very similar to the trivalent lanthanides [26] and have 3TBP molecules co-ordinated to $\mathrm{Gd}\left(\mathrm{NO}_{3}\right)_{3}$ in the extracted species. The overall chemical reaction is represented by the following set of equation:

$$
\mathrm{Gd}^{3+}{ }_{\mathrm{aq}}+3 \mathrm{NO}_{3}^{3}{ }_{\mathrm{aq}}+3 \mathrm{TBP}_{\mathrm{org}} \rightleftharpoons \mathrm{Gd}\left(\mathrm{NO}_{3}\right)_{3} \cdot 3 \mathrm{TBP}_{\text {org }}
$$

The apparent equilibrium constant, which is defined as the product of the equilibrium constant and the activity coefficients raised to appropriate power of stoichiometric coefficients as per Eq.(1) is represented as follows:

$$
\mathrm{K}_{\mathrm{Gd}}=\frac{\left[\mathrm{Gd}\left(\mathrm{NO}_{3}\right)_{3} \cdot 3 \mathrm{TBP}\right]}{\left[\mathrm{Gd}^{3+}\right]\left[\mathrm{NO}_{3}^{-}\right]^{3}\left[\mathrm{TBP}_{\mathrm{f}}\right]^{3}}
$$

The distribution coefficient of gadolinium is defined as,

$$
\begin{gathered}
\mathrm{D}_{\mathrm{Gd}}=\frac{\left[\mathrm{Gd}\left(\mathrm{NO}_{3}\right)_{3} \bullet 3 \mathrm{TBP}\right]}{\left[\mathrm{Gd}^{3+}\right]} \\
\mathrm{K}=\frac{\mathrm{D}_{\mathrm{Gd}}}{\left[\mathrm{NO}_{3}^{-}\right]^{3}\left[\mathrm{TBP}_{\mathrm{f}}\right]^{3}}
\end{gathered}
$$

Extraction behaviour of various gadolinium concentrations (1-5 g/L) from nitric acid solution of fixed concentration of $3.5 \mathrm{M}$ into TBP of three different concentrations (10, 20 and $30 \%$ by volume in $n$-dodecane) was investigated. The result presented in Fig.7 clearly indicates that the $D_{\mathrm{Gd}}$ decreases with increase in gadolinium concentration for a given TBP concentration and also it increases as a function of TBP for a given Gd(III) concentrations at equilibrium. As the gadolinium concentration used in this study was less, which was arrived at based on criticality safety calculations for the fissile material concentrations prevailing in typical fast reactor fuel reprocessing conditions, its loading is much lesser than the saturation limit of gadolinium loading. Hence, with increase in $\mathrm{Gd}(\mathrm{III})$ concentration $D_{\mathrm{Gd}}$ decreases.

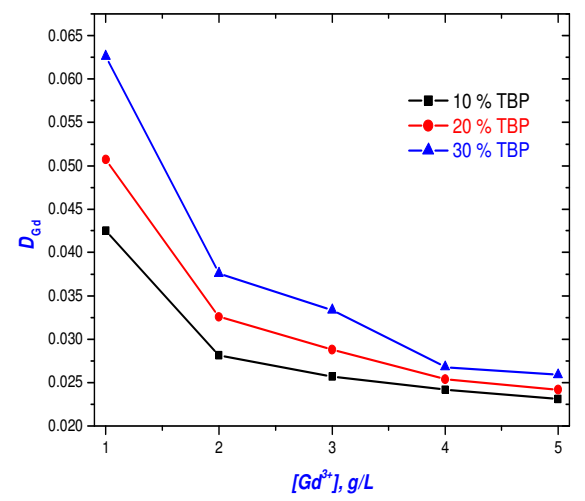


Fig.7 $D_{\mathrm{Gd}}$ as a function of $\mathrm{Gd}(\mathrm{III})$ concentration $(1-5 \mathrm{~g} / \mathrm{L})$ with different concentration of TBP from $3.5 \mathrm{M}$ nitric acid.

\section{CONCLUSIONS}

A new simple, sensitive, selective and inexpensive method for the determination of $\mathrm{Gd}^{3+}$ ions in nitric acid medium with Gd-ARS complex was developed relevant to PUREX process for continuous monitoring. This method does not require the use of expensive, toxic and carcinogenic organic solvents, less complicated when compared to others techniques. The accuracy and selectivity in terms of relative standard deviation of the present method are reliable for the determination of gadolinium in real samples to microgram levels in aqueous medium at room temperature $(25 \pm 5)^{\circ} \mathrm{C}$. The present method for determination of gadolinium is proposed, which possesses the advantages of high selectivity and sensitivity.

\section{REFERENCES}

[1] Natarajan, R., and Baldev Raj, Technology development of Fast Reactor Fuel Reprocessing in India, Current Science, 2015, vol. 108, pp. 30-38.

[2] Dutta, S., Suryanarayanan, P., Kandalgaonaker, A.R, Sharma, R.S, Bose, H., and Unny, V.K.P., Development of ion-exchange schemes for selective removal of gadolinium nitrate in the presence of Boron from the moderator system of 540 MWe PHWRs-TAPS 3 \&4. BARC newsletters, 2006, vol. 271, pp. 2-5.

[3] Vijayalakshmi, R., Singh, D.K., Kotekar, M.K. and Singh, H., Separation of high purity gadolinium for reactor application by solvent extraction process, J. Radioanal Nucl chem., 2014, vol. 300, pp. 129-135.

[4] Hill, J., Mitterdorfer, A., Kleinlogel, C., Perednis, D., and Gauckker, L., Fabrication of thin electrolytes for second-generation solid oxide fuel cells. J Soild State Ionics, 2007, vol. 131, pp. 79.

[5] Hennebruder, K., Wennrich, R., Mattusch, J., Stark, H.J., and Engewald, W., Determination of gadolinium in river water by SPE preconcentration and ICP-MS, Talanta, 2004, vol. 63, pp. 309.

[6] Salonia, J.A., Gasquez, J.A., Martinez, L.D., Cerutti, S., Kaplan, M., and Olsina, R.A., Inductively coupled plasma optical emission spectrometric determination of gadolinium in urine using flow injection on-line sorption pre-concentration in a Knotted reactor, Instru Sci Tech, 2006, vol. 34, pp. 305-316.

[7] Whitney, A.H., James, F.R., Mariah, B. and Tracy, P., Gadolinium deposition in nepherogenic systemic fibrosis: an examination of tissue using synchrotron $\mathrm{X}$ ray fluorescence spectroscopy, $\mathrm{J}$ Am Acad Dermatol, 2010, vol. 62, no. 1, pp. 38.

[8] Ishikawa, N., Tanaka, N., and Kaizu, Y., ESR study of sublevel structure of anionic bis(phthalocyaninato)gadolinium(III), Inorganic Chimica Acta, 2004, vol. 357, pp. 2181-2184.

[9] Grafe, J.L., McNeill, F.E., Byun, S.H., Chettle, D.R., and Noseworthy, M.D., A benchmarked MCNP model of the in vivo detection of gadolinium by prompt gamma neutron activation analysis. Nuclear Instrumentation Methods Physics Res B, 2010, vol. 268, pp. 2451-2457.

[10] Lei, L., Jinghe Yang, Xia Wu, Changxia Sun, Yang Liu, Shufang Liu, and Benyu Su., The fluorescence enhancement effect of TB-Gd-adenosine triphosphate-phen system and its analytical application. Talanta, 2005, vol. 65, pp. 201.

[11] Strasser, A. and Vogler, A., Phosphorescence of gadolinium(III) chelates under ambient conditions, Inorg Chim Acta, 2004, vol. 357, no. 8, pp. 2345-2348.

[12] Vahdani, M., Zamani, H.A. and Karimian, S., Quantitative determination of gadolinium ion by a Gd3+-Liquid membrane sensor based on 1-(4-nitrophenyl)-3-(4-phenylazophenyl) triazene as a sensing material, Int J Electrochem Sci., 2013, vol. 8, pp. 2734-2745.

[13] Zade, A.B. and Dhepe, A.S., Spectrophotometric micro determination of Gadolinium(III) and Terbium(III) with xylenol Orange in presence of cationic cetylpyridinium bromide as a surfactant, J Indian Chem Soceity, 2013, vol. 90, no. 9, pp. 1367-1378.

[14] Xiong, C. and Yao, C., Adsorption Behavior of MWAR Toward Gd(III) in Aqueous Solution, Iran J Chem Egg., 2010, vol. 29, pp. 59-66. 
[15] Dedkova, V.P., Shvoeva, O.P., and Savvin, S.B., Sorption-spectrophotometric determination of thorium(IV) and U(VI) with the reagent arsenazo III on the solid phase of a fibrous material filled with a cation exchanger. Journal of Analytical Chemistry, 2008, vol. 63, no. 5, pp. 430-434.

[16] Mahanwar, K.R., Sabale, S.R., Kadam, R.B., and Mohite, B.S., Reversed-phase column extractive separation of $\mathrm{Gd}(\mathrm{III})$ with poly[dibenzo-18-crown-6], International Journal of Inorganic Chemistry. 2012, doi.101155/2012/515196.

[17] Tarek, M., Zaki, M., Shoukry, A.F., and Hafez, M.B., Spectrophotometric determination of some lanthanides as tetra ethylene penta amine hepta acetic acid chelates, Analyst, 1983, vol. 108, pp. 531534.

[18] Asha Mathew, Krishna Kumar, A.V., Shyamala, P., Satyanarayana, A., and Rao, I.M., Spectrophotometric determination of neodymium(III), Samarium(III), Gadolinium(III), Terbium(III), Dysprosium(III), Holmium(III) in micellar media, Indian Journal Chem. Tech, 2012, vol. 19, pp. 331-336.

[19] Iljas, N., Hendrati, D., and Srigati, V., Separation and determination of gadolinium and cerium metals from monazite of Bangka Island by extraction following UV/Visible spectroscopy using di-nbuthydithiocarbamate as complex formation agent. Proceeding of the Int seminar on chemistry. 2008, pp. 93-99.

[20] Indah Raya, Ibrahim Baba, Bohari Mohd Yamin, Djulia Onggo, Gadolinium(III) Complexes with dialkyldithiocarbamates and 1,10-Phenantroline. Sains malaysiana journal, 2007, vol. 7, pp. 15-20.

[21] Martinez, L.D., Perino, E., Marchevsky, E.J., and Olsina, R.A., Spectrophotometric determination of gadolinium(III) with 2-(5-Bromo-2-pyridylazo)-5-diethylainophenol (5-Br-PADAP), Talanta, 1993, vol. 40, no. 3, pp. 385-390.

[22] Lepine, L., Gilbert, R., and Belanger, G., Ultraviolet spectrophotometric determination of gadolinium in concentrated solutions of nitrate salts, Anal.Chem., 1986, vol. 58, no. 6, pp. 1152-1156.

[23] Sangal, S.P., Metal chelates of lanthanoids in aqueous solution and their analytical applications, J Prakische Chemie, 1967, vol. 4, pp. 126-137.

[24] Sandell, E.B., (1950). Colorimetric determination of traces of metal. Chapter III, 2nd Edition, Interscience publishers, New York. 1950.

[25] IUPAC: Analytical chemistry Division, Spectrochimica Acta. 1978, vol. 33, pp. 242.

[26] Bednarczky, L., and Siekierski, S., Extraction of light lanthanide nitrates by tri-n-butyl phosphate. Solvent Extraction Ion Exchange, 1987, vol. 7, pp. 273-287. 